Georgia State University

ScholarWorks @ Georgia State University

\title{
Father Locus of Control and Child Emotional and Behavioral Outcomes: A Prospective Study
}

\author{
Erin Tone \\ Georgia State University, etone@gsu.edu \\ Stepanie Goodfellow \\ University of Bristol \\ Stephen Nowicki Jr. \\ Emory University
}

Follow this and additional works at: https://scholarworks.gsu.edu/psych_facpub

Part of the Psychology Commons

\section{Recommended Citation}

Tone, Erin; Goodfellow, Stepanie; and Nowicki, Stephen Jr., "Father Locus of Control and Child Emotional and Behavioral Outcomes: A Prospective Study" (2012). Psychology Faculty Publications. 112.

https://scholarworks.gsu.edu/psych_facpub/112

This Article is brought to you for free and open access by the Department of Psychology at ScholarWorks @ Georgia State University. It has been accepted for inclusion in Psychology Faculty Publications by an authorized administrator of ScholarWorks @ Georgia State University. For more information, please contact scholarworks@gsu.edu. 
Father Locus of Control and Child Emotional and Behavioral Outcomes: A Prospective Study

\author{
Erin B. Tone \\ Department of Psychology, Georgia State University, Atlanta, Georgia, USA \\ Stephanie Goodfellow \\ Department of Social Medicine, University of Bristol, Bristol, United Kingdom \\ School of Dental Sciences, University of Liverpool, Liverpool, United Kingdom \\ Stephen Nowicki, Jr. \\ Department of Psychology, Emory University, Atlanta, Georgia, USA
}

Address correspondence to Erin B. Tone, Department of Psychology, Georgia State University,

P.O. Box 5010, Atlanta, Georgia, U.S.A. 30302-5010; etone@gsu.edu (e-mail).

\title{
ARTICLE
}




\begin{abstract}
This prospective longitudinal study examined the associations between parent locus of control of reinforcement (LOCR), measured before the birth of a child, and behavioral/emotional outcomes in that child at age seven years. Three hundred seven couples completed questionnaires regarding their emotional status and LOCR at their first prenatal care appointment. When their children turned seven years old, teachers completed questionnaires regarding each participating child's behavior. Findings indicate significant associations between fathers' prenatal LOCR and child outcomes, particularly hyperactivity in sons. Hyperactivity and behavioral/emotional problems in girls, in contrast, were better predicted by maternal prenatal emotional distress. Results provide evidence that both paternal and maternal characteristics that predate the birth of a child relate to later behavioral outcomes in that child. Implications for prevention of child psychopathology are discussed.
\end{abstract}


For decades, researchers have called for more attention to fathers in research on child development (Cassano, Adrian, Veits, \& Zeman, 2006; Lamb, 1975; Phares \& Compas, 1992). In response, a growing literature documents how paternal characteristics (e.g., risk factors such mental illness and protective factors such as a warm parenting style) relate to child outcomes (Connell \& Goodman, 2002; Ramchandani, Stein, Evans, \& O'Connor, 2005; Skopp, McDonald, Jouriles, \& Rosenfield, 2007). This literature convincingly shows that fathers influence offspring emotions and behavior. It is thus critical that efforts to prevent child emotional/behavioral problems encourage education of fathers about their roles in healthy development.

To advance such prevention efforts, it is important to understand mechanisms underlying relationships between parent characteristics and child adjustment; these mechanisms, however, remain unclear. As Goodman and Gotlib (1999) proposed in their model of the transmission of risk from depressed mothers to offspring, both biological factors, such as genetics and neuroregulatory dysfunction, and environmental factors, such as exposure to negative parental cognitions, probably contribute in a dynamic fashion. Although such complex models have historically been applied primarily to mothers, they are also relevant to fathers.

Much research on relations between paternal variables and child emotional or behavioral outcomes has focused on paternal psychopathology. Findings indicate links between child internalizing and/or externalizing problems and the presence or history of varied psychiatric diagnoses in fathers (Brennan, Hammen, Katz, \& Le Brocque, 2002; Connell \& Goodman, 2002; Kane \& Garber, 2004; Ramchandani, Stein, Evans, \& O'Connor, 2005). Less attention, in contrast, has been directed toward other variables, such as personality features, that might predict child outcomes. In the present longitudinal study, we examined associations between one 
personality characteristic_-locus of control of reinforcement (LOCR)—-measured in fathers and mothers before a child's birth and behavioral/emotional outcomes in that child at seven years. Locus of Control of Reinforcement (LOCR)

Julian Rotter (Rotter, 1966) initiated the study of LOCR from a psychological perspective. According to Rotter, as a function of their learning histories, individuals vary along a spectrum of perceived control of reinforcement. At one end of the spectrum are "internally controlled" individuals, who endorse strong beliefs "that reinforcement . . . is contingent on their own behavior or personal characteristics” (Rotter, 1990, p. 489). At the other end are "externally controlled" individuals, who believe that reinforcement is "an outcome of change, luck, or fate, is under the control of powerful others, or is simply unpredictable” (Rotter, 1990, p. 489).

LOCR has become, since the 1960’s, a widely studied personality construct (Rotter, 1990). Most research, however, has focused on associations between an individual's own LOCR and a wide range of outcomes. For example, an internal LOCR in both children and adults reliably predicts academic achievement, social adjustment, and physical and emotional health (Chorpita, Brown, \& Barlow, 1998; Gale, Batty, \& Deary, 2008; Geist \& Borecki, 1982;

Kalechstein \& Nowicki, 1997). Internality also relates positively to information-seeking in such adverse conditions as imprisonment (Seeman, 1963) and to appraisals of oneself as good at problem-solving (Larson, Piersel, Imao, \& Allen, 1990). Thus, consistent with Rotter’s (1966) original model of LOCR as a generalized problem solving expectancy, individuals with more internal LOCRs appear more likely than those with external LOCRs to believe that they will successfully manage a range of difficult situations.

LOCR and Parenting Behavior 
Child-rearing presents mothers and fathers with an array of daunting problems to solve. Early parenthood not only requires adjustment to lifestyle and relationship changes, including sleep deprivation and increased marital stress, but also demands mastery of novel caregiving tasks (Cowan \& Cowan, 2000; Feeney, Hohaus, Noller, \& Alexander, 2001). Later, parents must develop and adapt behavior management strategies. How parents approach these problems has marked implications for the child. Not only do negative parenting styles, such as excessive harshness or laxity, predict negative child outcomes, such as anxiety or externalizing behavior (Bayer, Hiscock, Ukoumunne, Price, \& Wake, 2008; Hipwell et al., 2008; Miner \& ClarkeStewart, 2008), but positive parenting styles, marked by warmth and good boundaries, relate to positive child outcomes, such as empathy or prosocial behavior (Davidov \& Grusec, 2006).

Many variables likely influence how parents negotiate childrearing challenges. LOCR, conceptualized as a generalized problem solving expectancy, is a plausible contributing factor (Gerdes et al., 2007). For example, parents who perceive their children’s difficult behaviors as under their control may feel more confident in their own abilities to elicit changes in those behaviors than do parents who do not. Such beliefs, in turn, may promote the use of effective child-rearing strategies. Further, research has found that parents who perceive themselves as having limited control over their own environments before a child's birth are more likely to feel depressed or anxious during their first year of parenthood (Keeton, Perry-Jenkins, \& Sayer, 2008). Taken together with the large literature linking parent internalizing symptoms and risk for adverse child outcomes (S. H. Goodman, Brand, Hersen, \& Gross, 2008), these findings raise the possibility that parent prenatal cognitive characteristics contribute to offspring mental health.

To examine this possibility, researchers have used both generalized LOCR measures and measures of parenting LOCR that measure parents' perceptions of whether their children's 
feelings, thoughts, and behavior are under their control (Campis, Lyman, \& Prentice-Dunn, 1986). Studies that have used parenting LOCR measures have found an external LOCR to relate to risk for harsh or abusive (Bugental, Blue, \& Cruzcosa, 1989; Rodriguez \& Richardson, 2007; Stringer \& La Greca, 1985), lax (Gerdes et al., 2007), and generally ineffective parenting (Banks, Ninowski, Mash, \& Semple, 2008). It remains unclear, however, how parent LOCRs relate to child behavior patterns. This question merits prospective study, given the likely reciprocal influences among parent cognitions, parenting style, and child characteristics and behaviors.

\section{Parent LOCR and Child Outcomes}

Little is known about how parents’ LOCR or patterns of problem-solving expectancies relate to outcomes in their children, particularly over time. The few published studies have used cross-sectional, rather than prospective, longitudinal designs, making it hard to clarify how parent cognitive styles that predate a child's birth relate to child thoughts, feelings, and actions. Some evidence does indicate concurrent associations between parenting LOCR and child behavior. For example, parents seeking help in managing child behavior problems reported more external parenting LOCRs than did parents who reported no parenting difficulties (Campis, Lyman, \& Prentice-Dunn, 1986). Similarly, in families presenting for treatment of oppositional child behavior, parents of more coercive children reported more external parenting LOCRs than did parents of less coercive youths (Roberts, Joe, \& Rowe-Hallbert, 1992). One study obtained similar results in a non-clinical sample; external parenting LOCR and parent-reported behavior correlated significantly with problems in non-referred children (Morton, 1997). Notably, although most studies have found that an external parent LOCR relates to externalizing behavior in youth, one study found associations between parent externality and parent-reported internalizing behavior (Wheatcroft \& Creswell, 2007). 
The studies described above are limited on several fronts. First, they used cross-sectional designs that precluded examination of directional effects. Parents of children with difficult temperamental styles, for example, may be especially likely to perceive that their control over their children’s behavior as limited, based on failed efforts at behavior management rather than on enduring and pervasive cognitive features. In other words, children's behavior may influence their parents' LOCR orientations. Alternatively, adults who lack a sense of control over their environments may approach parenting in a more lax, harsh, or inconsistent manner regardless of child characteristics. A third possibility is that parent LOCR and parenting style interact dynamically with child characteristics, such that each influences the other.

Longitudinal research provides some evidence that parent control perceptions may contribute independently to child behavior. In one longitudinal study that followed 89 children from six weeks until nine years of age, external parenting LOCRs in both mothers and fathers when the child was 33 months old predicted negative child behavior in four and nine year olds (Hagekull, Bohlin, \& Hammarberg, 2001). However, because parents did not report their LOCRs until their children were nearly 3 years old, it is unclear whether child characteristics influenced parent control perceptions. Indeed, the degree to which parents described their children as "manageable" during their first year of life related significantly to parenting LOCR at 33 months.

A second limitation of most studies of parent LOCR and child outcomes is that they typically have obtained only parent reports of child behavior. Such failure to solicit data from outside observers raises the risk that parent reports of child behavior may be biased by the variables under study. For instance, parents with more external LOCRs may have been more likely to perceive their children as difficult, regardless of actual behavior patterns. In the one 
observational study of parent LOCR and child behavior, mothers with more external LOCRs behaved controllingly during play with their 20-month old children (Fagiolini et al., 2005). Prospective Examination of Parent LOCR Orientation and Child Outcomes

The present study was designed to address some of the limitations of earlier research on parent LOCR and child behavior. First, the prospective longitudinal design, in which measures of parent LOCR were gathered before the birth of the child, ensures that child characteristics did not influence parents' LOCR reports. Second, the inclusion of prenatal self-reports of both mother and father LOCRs permits examination of associations between child outcomes and the cognitive problem solving styles of both parents. Third, the use of teacher rather than parent reports of child behavior at age seven decreases the likelihood that parent LOCR or other associated psychological variables might have influenced perceptions of children's behavior.

Our central hypothesis was that more external prenatal LOCRs in mothers and fathers would predict more negative child outcomes, including more emotional and behavioral problems, as well as more hyperactivity. We anticipated that these associations would remain significant when potential confounds, such as parent education, prenatal anxiety, depression, and stress were covaried. Based on evidence that associations between parent LOCR and child outcomes may differ based on child sex (Draper, 1982), we conducted all analyses both for the sample as a whole and separately for boys and girls.

\section{Method}

\section{Participants}

Participants consisted of 307 seven to eight year old children (52.4\% male) and their parents, all of whom were enrolled in the European Longitudinal Study of Pregnancy and Childhood (ELSPAC). ELSPAC, a multi-site, geographically based, longitudinal study, 
designed to measure health, development, and parenting of young children in Europe which involves 40,000 children born between 1991 and 1992 in ten different European sites, including the Isle of Man (IOM). All families that participated in the present study were residents of the IOM, an autonomous country (population estimated at 75,831 as of July 2007) that lies in the Irish Sea, equidistantly 80 miles from Ireland, Scotland, and England.

Every woman in the IOM who was expected to deliver a baby between January 1991 and June 1992 ( $\mathrm{N=1400)}$ was invited to join the study; of these mothers, 1391 had been enrolled by the time of delivery. Of these 1391 mothers, 39 (2.7\%) left the island prior to delivery and 37 (2.7\%) miscarried, leaving 1315 mothers and 1330 live born infants available for study at delivery. Participating mothers and their partners (98\% of whom were the biological fathers of the target child) were asked to complete questionnaires at three time points prior to delivery (initial enrollment, 32 weeks gestation, 36 weeks gestation). Participants were only included in analyses for the present study if a) complete demographic data were available for both mother and father, b) both mothers and fathers fully completed initial prenatal measures, and c) teacher reports regarding their child’s behavior were available at 7 year follow-up. These inclusion criteria yielded a final sample of 307 families (mother, father, and child). For families with twins enrolled in the study, one of the two twins was randomly selected for inclusion in the present analyses and the other excluded. Demographic data at the time of study enrollment for mothers and fathers in the final sample are presented in Table 1. Most parents (81\%) were married, approximately two-thirds reported that the index pregnancy was planned (66.7\%), and roughly half reported that the index child was their first (46.9\%; data were missing for two families). T-test results indicate that mothers were significantly younger than fathers, $\mathrm{t}(307)=$ 8.79, $\mathrm{p}<.001$. Wilcoxon Matched Pairs Signed Rank Test results yielded no significant 
differences between mothers and fathers in education levels, $\mathrm{Z}=1.76, \mathrm{p}=.08$, or ethnicity, $\mathrm{Z}=$ 1.19, $\mathrm{p}=.23$.

Demographic data for participating children are presented in Table 2. Boys $(n=161)$ and girls $(n=146)$ did not differ significantly in age, $\mathrm{t}(307)=0.34, \mathrm{p}>.05$, first-born status, $\chi^{2}=$ 1.09, $\mathrm{p}>.05$, mothers’ education, Mann-Whitney $\mathrm{U}=10855, \mathrm{z}=-1.19, \mathrm{p}>.05$, or fathers’ education, Mann-Whitney $\mathrm{U}=11539$, $\mathrm{z}=-0.28, \mathrm{p}>.05$.

\section{Procedures}

This study was approved by all relevant Ethical Committees; all participating parents provided informed consent and all participating children provided assent. At initial presentation for prenatal care (typically 16-18 weeks gestation), pregnant women were invited to participate in the study. Once enrolled, participating mothers and their partners completed questionnaires that included measures regarding their demographic status, their emotional and physical health, their relationships with each other, their reactions to impending parenthood, and their LOCRs. Mothers and their partners completed further questionnaires at multiple subsequent time points, two prior to delivery [32 weeks gestation (mother only), 36 weeks gestation] and six post-natally (six weeks, six months, eighteen months, three years, five years, seven years). For the present study, only the parent measures gathered at initial presentation for prenatal care were used in analyses to maximize the number of participants with complete data. When children of participating parents reached the age of seven years, their teachers completed both the Strengths and Difficulties Questionnaire (SDQ; R. Goodman, 1997; R. Goodman, Ford, Simmons, Gatward, \& Meltzer, 2000) and the Hyperactivity/Inattention section of the Development and Well Being Assessment (DAWBA; R. Goodman, Ford, Richards, Gatward, \& Meltzer, 2000) for 
each child (DAWBA data were incomplete for two children, thus analyses focused on the DAWBA include only 305 participants).

\section{Measures}

Locus of Control Scale. Twelve items from the Adult Nowicki Strickland Internal External Control Scale (ANSIE; Nowicki \& Duke, 1974) were used to assess parents’ LOCR prior to the target child's birth. Higher scores indicate a more external orientation, and lower scores indicate a more internal orientation. Researchers have used various forms of the ANSIE, which has satisfactory internal consistency and test-retest reliability (Nowicki \& Duke, 1974), in over 1400 studies. The 12 items used in the present study were selected from the original 40item form based on item statistics obtained in pilot research $(n=127)$. Findings indicated a correlation of .78 between scores on the 12-item and 40-item forms; further, the 12-item form yielded a coefficient alpha of .83.

Crown-Crisp Experiential Index (CCEI; Crown \& Crisp, 1979). This standardized measure of affective symptoms, which includes subscales focused on anxiety, depression, and somatization, was administered to both mothers and fathers. The measure demonstrates good reliability (Alderman, Mackay, Lucas, Spry, \& Bell, 1983), as well as acceptable convergent and divergent validity (Birtchnell, Evans, \& Kennard, 1988; Burgess, Mazzocco, \& Campbell, 1987). Total score from the measure served as a predictor in analyses.

Strengths and Difficulties Questionnaire Teacher Form 4-16 ${ }^{1}$ (SDQ T 4-16; R. Goodman, 1997; R. Goodman, Ford, Simmons, Gatward, \& Meltzer, 2000): The SDQ T 4-16 is a 25-item, teacher-completed questionnaire that screens for a variety of behaviors, both positive and negative, in children and adolescents. The measure comprises five subscales (Emotional Symptoms, Conduct Problems, Hyperactivity/Inattention, Peer Relationship Problems, and 
Prosocial Behavior); scores from the first four subscales can be summed to create a Total Difficulties score, with higher scores indicating more problem behavior. Data from a large epidemiological sample in Great Britain $(n=10,438)$ indicate satisfactory internal consistency reliability (mean Cronbach's alpha: 0.73), cross-informant correlation (mean: 0.34), and stability over a 4-6 month period (mean: 0.62) (Meltzer, Gatward, Goodman, \& Ford, 2000). Total Difficulties score served as a primary outcome variable in the present study.

Development and Well Being Assessment (DAWBA) Hyperactivity-Inattention Questionnaire (R. Goodman, Ford, Richards, Gatward, \& Meltzer, 2000): Teachers completed this measure, which comprises 18 questions regarding hyperactive and inattentive behavior, when child participants were 7 years old. Findings from a national survey of youths in Great Britain provide evidence of the measure's reliability and validity (R. Goodman, Ford, Richards, Gatward, \& Meltzer, 2000).

\section{Statistical Analysis}

Prior to analysis, data were examined to evaluate fit between the distributions of the variables and the assumptions of multivariate analysis. Residuals were examined and skewness and kurtosis were tested. Significant skewness was evident for SDQ Total Score $(Z=9.96, p<$ .01), DAWBA Total Score $(Z=5.64, \mathrm{p}<.01)$, prenatal maternal CCEI score $(\mathrm{Z}=11.81, \mathrm{p}<.01)$, prenatal paternal CCEI score $(Z=5.09, \mathrm{p}<.01)$, and paternal ANSIE score $(Z=2.76, p<.01)$; consequently, all five variables were log transformed after the addition of a constant value of 10 to each.

Student's t-tests were conducted to examine potential sex differences in children's SDQ and DAWBA scores. Paired-sample t-tests were also conducted to compare mother and father scores on the CCEI and ANSIE. Primiparous and multiparous parents were also compared on 
CCEI and ANSIE scores using Student’s t-tests. Finally, hierarchical multiple regression analyses were conducted examining prenatal maternal and paternal LOCR, as measured by selfreported ANSIE scores, as predictors of teacher-reported child scores on the SDQ (total and subscale scores) and DAWBA total score when the child was 7-8 years of age.

Covariates for all regression analyses (mother and father ages and education levels) were selected based both on previous findings in the IOM ELSPAC study (Goodfellow, 1996) showing that demographic variables relate significantly to numerous parent and child outcomes and Spearman correlations in the present sample among the outcome variables (SDQ and DAWBA total scores), demographic variables (mother's and father's ages and education levels) and both parents’ prenatal CCEI scores (see Table 3). Demographic variables (mother’s and father's ages and education levels) were entered at the first step, mother and father prenatal CCEI scores at the second step, mother and father ANSIE scores at the third step, and the interaction terms for child sex $\mathrm{x}$ mother ANSIE score and child sex $\mathrm{x}$ father ANSIE score at the fourth step.

\section{Results}

T-test results indicated significant differences between boys and girls on total SDQ ( $<$ < $.001)$ and DAWBA scores $(\mathrm{p}<.001)$, with males obtaining significantly higher scores on both scales (see Table 2). Boys also scored higher on the SDQ Prosocial Behavior $(\mathrm{p}<.001)$, Activity Level $(\mathrm{p}<.001)$, and Conduct Problems $(\mathrm{p}<.001)$ subscales. No significant differences were evident between boys and girls on the Anxiety or Peer Relations subscales (p > $.05)$.

Significant differences were evident between mothers and fathers on the prenatally administered CCEI, with mothers reporting more symptoms than fathers, t $(307)=12.38, \mathrm{p}<$ .01. CCEI scores did not, however, differ between primiparous and multiparous mothers, t(305) 
$=-0.36, \mathrm{p}>.05$, or fathers, $\mathrm{t}(305)=-0.65, \mathrm{p}>.05$. Mothers and fathers did not differ significantly in their self-reported LOCRs, $\mathrm{t}(307)=1.25, \mathrm{p}>.05$. No significant differences on the ANSIE were evident between primiparous and multiparous mothers, $t(305)=-1.70, p=.09$, or fathers, $\mathrm{t}(305)=0.69, \mathrm{p}=.49$.

Regression results

For the first regression analysis, predicting DAWBA total score from mother and father ANSIE scores, R differed significantly from zero at the end of each of the four steps. At the first step, the model including only demographic variables significantly predicted child DAWBA scores, $\mathrm{R}^{2}$ Adj $=.05, \mathrm{~F}(4,300)=5.30, \mathrm{p}<.01$, Cohen's $f^{2}=.07$. The model at step 2 , which added mother and father CCEI scores, although significant, $\mathrm{R}^{2}$ Adj $=.05, \mathrm{~F}(6,298)=3.75, \mathrm{p}<.01$, Cohen's $f^{2}=.08$, did not reliably improve $\mathrm{R}^{2}$ dj, $\mathrm{F}_{\Delta}(2,298)=0.58, \mathrm{p}=.56$. At step 3 , when parent ANSIE scores were added, the model was both significant, $\mathrm{R}^{2}$ Adj $=.08, \mathrm{~F}(8,296)=4.07, \mathrm{p}$ $<.001$, Cohen's $f^{2}=.11$, and $\mathrm{R}^{2}$ Adj was significantly improved over step $2, \mathrm{~F}_{\Delta}(2,296)=4.74, \mathrm{p}<$ .01. Of the predictor variables in the equation at step 3, only fathers' LOCR, as indexed by ANSIE score, accounted independently for a significant proportion of the variance, $b=.02, \beta=$ 0.19, $\mathrm{t}=3.08, \mathrm{p}<.01$. Finally, at step 4 , when the interactions between child sex and parent ANSIE scores were included in the model, results were significant, $\mathrm{R}^{2}$ Adj $=.15, \mathrm{~F}(10,294)=$ 6.52, $\mathrm{p}<.001$, Cohen's $f^{2}=.22$. Of the predictor variables in the equation at step 4, only fathers' LOCR, as indexed by ANSIE score, and the interaction between child sex and fathers’ LOCR accounted independently for significant proportions of the variance, fathers' LOCR: $b=2.38, \beta=$ 0.44, $\mathrm{t}=2.84, \mathrm{p}<.01$; child sex $\mathrm{x}$ father's LOCR: $\mathrm{b}=-1.13, \beta=-0.34, \mathrm{t}=-2.08, \mathrm{p}<.05$.

Results of the regression analysis predicting SDQ total score from mother and father ANSIE scores show that, as in the model predicting DAWBA scores, R differed significantly 
from zero at each of the four steps. At the first step, the model including only demographic variables significantly predicted child SDQ scores, $\mathrm{R}^{2}$ Adj $=.04, \mathrm{~F}(4,302)=4.62, \mathrm{p}<.01$, Cohen's $f^{2}=.06$. The model at step 2 , which added mother and father CCEI scores, was significant, $\mathrm{R}_{\text {Adj }}^{2}=.05, \mathrm{~F}(6,300)=3.44, \mathrm{p}<.01$, Cohen's $f^{2}=.07$, but did not reliably improve $\mathrm{R}_{\text {Adj, }}^{2} \mathrm{~F}_{\Delta}(2,300)=1.07, \mathrm{p}=.34$. The addition of parent ANSIE scores at step 3 yielded a significant model, $\mathrm{R}^{2}$ Adj $=.06, \mathrm{~F}(8,298)=3.29, \mathrm{p}<.01$, but $\mathrm{R}^{2}$ Adj was not significantly improved over step $2, \mathrm{~F}_{\Delta}(2,298)=2.75, \mathrm{p}=.07$. Of the predictors at step 3 , only fathers' LOCR, $b=0.29, \beta=0.14, t=2.26, p<.05$, and mothers' education, $b=-0.02, \beta=-0.14, t=-2.03, p<$ .05 accounted independently for a significant proportion of the variance. At step 4, when the interactions between child sex and parent ANSIE scores were included in the model, results were significant, $\mathrm{R}^{2}$ Adj $=.10, \mathrm{~F}(10,296)=4.44, \mathrm{p}<.001$, Cohen's $f^{2}=.15$. However, no predictor variables in the equation at step 4 accounted independently for significant proportions of the variance in SDQ score (all p’s > .05).

To rule out the possibility that parenting experience might have influenced parents’ LOCRs, we re-conducted regression analyses predicting DAWBA and SDQ scores, limiting the sample to first-born children ( $n=142)$. Results did not differ from those presented above. Regression results: DAWBA scores examined separately by child sex

Because the interaction term for child sex and father ANSIE score significantly predicted DAWBA scores, we conducted regression analyses predicting this variable separately for boys and girls, in an effort to decompose the interaction. The regression analysis predicting boys’ DAWBA scores from mother and father ANSIE scores yielded R values that differed significantly from zero at the end of each of the three steps. At the first step, the model including only demographic variables significantly predicted boys’ DAWBA scores, $\mathrm{R}^{2}{ }_{\text {Adj }}=.07, \mathrm{~F}(4,155)$ 
$=4.07, \mathrm{p}<.01$, Cohen's $f^{2}=.10$. The model at step 2 , which added mother and father CCEI scores, was significant, $\mathrm{R}^{2}$ Adj $=.07, \mathrm{~F}(6,153)=2.90, \mathrm{p}=.01$, Cohen's $f^{2}=.11$, but did not reliably improve $\mathrm{R}_{\text {Adj, }}^{2} \mathrm{~F}_{\Delta}(2,153)=0.60, \mathrm{p}=.55$. The addition of parent ANSIE scores at step 3 yielded a significant model, $\mathrm{R}^{2}$ Adj $=.08, \mathrm{~F}(8,151)=2.72, \mathrm{p}<.01$, Cohen's $f^{2}=.14$, but $\mathrm{R}^{2}$ Adj was not significantly improved over step $2, \mathrm{~F}_{\Delta}(2,151)=2.05, \mathrm{p}=.13$. Of the predictor variables in the equation at step 3, only fathers' LOCR, $b=.56, \beta=.17, t=2.00, \mathrm{p}<.05$, accounted independently for a significant proportion of the variance.

For girls, as for boys, the regression analysis predicting DAWBA scores yielded R values that differed significantly from zero at each step. At the first step, the model including only demographic variables significantly predicted girls’ DAWBA scores, $\mathrm{R}_{\text {Adj }}^{2}=.05, \mathrm{~F}(4,140)=$ 2.95, $\mathrm{p}<.05$, Cohen's $f^{2}=.08$. The model at step 2 , which added mother and father CCEI scores, was significant, $\mathrm{R}^{2}$ Adj $=.12, \mathrm{~F}(6,138)=3.88, \mathrm{p}<.01$, Cohen's $f^{2}=.12$, and reliably improved $\mathrm{R}_{\text {Adj, }}^{2} \mathrm{~F}_{\Delta}(2,138)=5.38, \mathrm{p}<.01$. The addition of parent ANSIE scores at step 3 yielded a significant model, $\mathrm{R}^{2}$ Adj $=.10, \mathrm{~F}(8,136)=3.01, \mathrm{p}<.01$, Cohen's $f^{2}=.18$, but $\mathrm{R}^{2}$ Adj was not significantly improved, $\mathrm{F}_{\Delta}(2,136)=0.48, \mathrm{p}=.62$. Of the variables at step 3 , fathers' education, $b=-.06, \beta=-.25, t=-2.64, p<.01$, and mothers' CCEI scores, $b=.37, \beta=.26, t=2.97, p<$ .01 , accounted for significant proportions of the variance.

\section{Discussion}

Results of the present study suggest that, as predicted, fathers’ LOCR measured prenatally significantly, predicts teacher-reported child emotional/behavioral symptoms and hyperactivity at age 7, such that paternal externality relates to higher levels of behavior problems. For teacher-reported hyperactivity, however, this relationship appears stronger for sons than for daughters. Specifically, separate analyses by child sex revealed that fathers' LOCR 
externality significantly, if modestly, predicted hyperactivity in boys, but not girls. For girls, in contrast, only maternal emotional symptoms and fathers' education level significantly predicted hyperactivity. Maternal LOCR was not associated with child outcomes for boys or girls.

These findings are notable in several respects. First, they are among the first to show that parent cognitive and emotional characteristics, measured before the birth of a child, relate reliably to later teacher-rated behavioral outcomes. Strikingly, paternal external LOCR emerged, along with maternal emotional symptoms and parent education, as one of the strongest predictors of later child behavioral/emotional problems, which underscores the need to include both parents in research focused on antecedents of child behavior patterns. Researchers have long called for studies of child outcomes to take fathers into account and the present findings provide evidence that omitting fathers may obscure important patterns of association.

Second, these findings indicate that relationships among parent characteristics and child behavioral/emotional outcomes are complex and vary as a function of both parent and child sex. More precisely, they suggest sex-linked associations, such that aspects of fathers’ prenatal cognitive styles relate more closely to outcomes in sons, while maternal prenatal emotional states relate more tightly to outcomes in daughters.

There are several possible explanations for the association between fathers' external LOCR and offspring hyperactivity. First, consistent with findings of a link between symptoms of attention deficit hyperactivity disorder (ADHD) and external LOCR in mothers (Banks, Ninowski, Mash, \& Semple, 2008), fathers with more external LOCRs may be more hyperactive than fathers with more internal LOCRs. They may thus confer on their offspring a risk for hyperactivity that is mediated both by genetics and by environmental factors, such as modeling or ineffective parenting. Second, fathers with more external LOCRs may be prone to respond 
ineffectively to challenging child behavior, as a function of a belief that such behavior is beyond their control. Thus, faced with hyperactive children, these fathers may engage in harsh and punitive parenting that exacerbates children’s tendencies to act out or behave impulsively (Johnston \& Mash, 2001). Alternatively, externally oriented fathers may respond to difficult child behavior by disengaging, which has also been linked to child hyperactivity (Flouri, 2008).

More puzzling is the finding that an external LOCR in fathers predicts hyperactivity in sons, but not daughters. Social learning theory (e.g., Bandura \& Walters, 1959) provides one potential explanation by postulating that children are likely to identify more closely with their same-sex parent, whose behavior is thus likely to be more influential. According to this model, hyperactive behavior or harsh/punitive parenting in fathers may elicit different, potentially stronger responses from sons. In a Chinese sample, for example, harsh fathering predicted aggression more strongly in sons than in daughters (Chang, Schwartz, Dodge, \& McBrideChang, 2003), and other research has shown dysfunctional fathering to relate more generally to externalizing behavior in sons, but not daughters (Verlaan \& Schwartzman, 2002).

For daughters in the present study, prenatal maternal anxiety, depression, and stress were the best predictors of both hyperactivity and emotional/behavioral problems. This is consistent with earlier findings linking adverse child outcomes and prenatal maternal depression (Luoma et al., 2001), anxiety (O'Connor, Heron, \& Glover, 2002; Van den Bergh \& Marcoen, 2004), and stress (Anhalt, Telzrow, \& Brown, 2007). To our knowledge, however, the present study is the first to find maternal prenatal emotional state to specifically predict outcomes in daughters.

Notably, parent education levels were the only other significant predictors of child outcomes; children of less educated mothers exhibited more behavioral/emotional difficulties and daughters of less educated fathers were more hyperactive. Like LOCR externality, low 
levels of parental education and other markers of low family socioeconomic status have been linked via maladaptive parenting to behavior problems in children (Dodge, Pettit, \& Bates, 1994). Education has also been found to correlate consistently with LOCR, with externally oriented individuals achieving less academically than internally oriented peers (Findley \& Cooper, 1983; Kalechstein \& Nowicki, 1997). It may thus be that external LOCR, limited education, and emotional distress converge to predict any of an array of offspring problems. How such problems manifest, in turn, appears to reflect a complex interplay with both parent and child sex.

Although the present study has numerous strengths, including a longitudinal design, a large community sample, and the use of teacher evaluations of child behavior, it also has limitations that future research should address. First, no data were available regarding parent LOCR and emotional status when children's behavior was evaluated at age seven. Controlling for parent LOCR and emotional state measured concurrently or at least at some point after the target child's birth, would have provided a stronger test of the hypothesis that prenatal parent cognitive/emotional patterns predict later child outcomes.

A second limitation of the present study is the lack of data regarding child LOCR. Such data would have allowed us to test whether child cognitions mediate associations between parent variables and child outcomes. Findings from small studies regarding links between parent/child LOCRs are inconsistent (Ackerman \& Ackerman, 1989; Hoffman \& Levy-Shiff, 1994; Morton, 1997), but given evidence that parents transmit maladaptive cognitive patterns to their children (Garber, Martin, Goodman, \& Gotlib, 2002), this association warrants further investigation. Collection of LOCR data from the child participants in this study (now age 16) is underway, which will allow us to examine predictive associations between parent and offspring LOCR. 
A third limitation is that our use of a generalized rather than a parenting LOCR measure makes it hard to compare our findings directly with those of many earlier studies. Although scores on generalized and parenting-specific LOCR measures correlate moderately, they relate differently to reports of parenting behaviors and experiences (Campis, Lyman, \& Prentice-Dunn, 1986; Gerdes et al., 2007). Rotter (1966), however, conceptualized LOCR as a generalized problem solving expectancy that should apply across an array of novel or ambiguous circumstances. This broad construct is thus more likely to tap thoughts/behaviors that relate in indirect ways to child outcomes than is the circumscribed construct of parenting LOCR. Future work might include both types of LOCR measure to clarify how they overlap and differ.

Finally, although the use of a relatively homogeneous, geographically-bound sample can confer advantages with regard to a study’s internal validity, it has the potential of limiting external validity. Our results should thus be generalized to other populations only with caution. Further, it would be useful to see the present findings replicated in samples drawn from other, more diverse populations.

The present findings provide evidence that paternal characteristics beyond psychopathology are relevant to their children’s healthy development and that, consistent with prior research, such characteristics can be identified prior to a child’s birth (e.g., Steele, Steele, \& Fonagy, 1996). They thus underscore the importance of targeting fathers, as well as mothers, in efforts to prevent and intervene in child behavioral and emotional problems. Further, they suggest that prenatal screens for personality characteristics, such as LOCR, may be useful to identify expectant fathers who might benefit from extra parenting education. Some evidence suggests that men may be less likely than women to report emotional symptoms, particularly when they believe they will be pushed to seek help (Sigmon et al., 2005). Reporting personality 
features, in contrast, may feel less threatening. Thus, combining LOCR questionnaires with prenatal screens for depression or anxiety might permit identification of more individuals, particularly males, who need extra support during the transition to parenthood. More broadly, the present findings highlight the need for prenatal education for both parents that focuses on childrearing, not just delivery and birth, and that actively teaches about effective parenting techniques and barriers to their implementation. 


\section{AUTHOR NOTES}

Erin Tone is an assistant professor in the Department of Psychology at Georgia State University in Atlanta Georgia. Stephanie Goodfellow is a professor in the School of Clinical Science at the University of Liverpool in England. Stephen Nowicki Jr. is the Charles Howard Candler Professor of Psychology in the Department of Psychology at Emory University in Atlanta, Georgia. 
Father Locus of Control 23

\section{REFERENCES}

Ackerman, L., \& Ackerman, P. L. (1989). Generational differences and parent-child resemblance in achievement motives and locus of control: A cross-sectional analysis. Personality and Individual Differences, 10(12), 1237-1242. doi:10.1016/0191-8869(89)90235-3

Alderman, K. J., Mackay, C. J., Lucas, E. G., Spry, W. B., \& Bell, B. (1983). Factor analysis and reliability studies of the Crown-Crisp Experiential Index (CCEI). British Journal of Medical Psychology, 56(Pt 4), 329-345. doi:10.1016/0191-8869(90)90259-T

Anhalt, K., Telzrow, C. F., \& Brown, C. L. (2007). Maternal stress and emotional status during the perinatal period and childhood adjustment. School Psychology Quarterly, 22, 74-90. doi:10.1037/1045-3830.22.1.74

Bandura, A., \& Walters, R. H. (1959). A study of the influence of child rearing practices and family interrelationships. New York: Ronald Press.

Banks, T., Ninowski, J. E., Mash, E. J., \& Semple, D. L. (2008). Parenting behavior and cognitions in a community sample of mothers with and without symptoms of attentiondeficit/hyperactivity disorder. Journal of Child and Family Studies, 17(1), 28-43. doi: 10.1007/s10826-007-9139-0

Bayer, J. K., Hiscock, H., Ukoumunne, O. C., Price, A., \& Wake, M. (2008). Early childhood aetiology of mental health problems: a longitudinal population-based study. Journal of Child and Adolescent Psychology and Psychiatry, 49, 1166-1174. DOI: 10.1111/j.14697610.2008.01943.x

Birtchnell, J., Evans, C., \& Kennard, J. (1988). The total score of the Crown-Crisp Experiential Index: a useful and valid measure of psychoneurotic pathology. British Journal of Medical Psychology, 61(Pt 3), 255-266. 
Brennan, P. A., Hammen, C., Katz, A. R., \& Le Brocque, R. M. (2002). Maternal depression, paternal psychopathology, and adolescent diagnostic outcomes. Journal of Consulting and Clinical Psychology, 70(5), 1075-1085. doi: 10.1037/0022-006X.70.5.1075

Bugental, D. B., Blue, J., \& Cruzcosa, M. (1989). Perceived control over caregiving outcomes: Implications for child abuse. Developmental Psychology, 25(4), 532-539.

Burgess, P. M., Mazzocco, L., \& Campbell, I. M. (1987). Discriminant validity of the CrownCrisp Experiential Index. British Journal of Medical Psychology, 60(Pt 1), 61-69.

Campis, L. K., Lyman, R. D., \& Prentice-Dunn, S. (1986). The Parental Locus of Control Scale: Development and validation. Journal of Clinical Child Psychology, 15(3), 260-267.

Cassano, M., Adrian, M., Veits, G., \& Zeman, J. (2006). The inclusion of fathers in the empirical investigation of child psychopathology: An update. Journal of Clinical Child and Adolescent Psychology, 35(4), 583-589. doi: 10.1207/s15374424jccp3504_10

Chang, L., Schwartz, D., Dodge, K. A., \& McBride-Chang, C. (2003). Harsh parenting in relation to child emotion regulation and aggression. Journal of Family Psychology, 17(4), 598-606. doi: 10.1037/0893-3200.17.4.598

Chorpita, B. F., Brown, T. A., \& Barlow, D. H. (1998). Perceived control as a mediator of family environment in etiological models of childhood anxiety. Behavior Therapy, 29, 457-476. doi:10.1016/S0005-7894(98)80043-9

Connell, A. M., \& Goodman, S. H. (2002). The association between psychopathology in fathers versus mothers and children's internalizing and externalizing behavior problems: A metaanalysis. Psychological Bulletin, 128(5), 746-773. doi: 10.1037/0033-2909.128.5.746

Cowan, C. P., \& Cowan, P. A. (2000). When partners become parents: The big life change for couples. Mahwah, NJ: Erlbaum. 
Crown, S., \& Crisp, A. H. (1979). Manual of the Crown-Crisp Experiential Index. London: Hodder and Stoughton.

Davidov, M., \& Grusec, J. E. (2006). Untangling the links of parental responsiveness to distress and warmth to child outcomes. Child Development, 77(1), 44-58. doi: 10.1111/j.14678624.2006.00855.x

Dodge, K. A., Pettit, G. S., \& Bates, J. E. (1994). Socialization mediators of the relation between socioeconomic status and child conduct problems. Child Development, 65(2), 649-665. doi : $10.2307 / 1131407$

Draper, T. W. (1982). Sons, mothers, and externality: Is there a father effect? Child Study Journal, 12(4), 271-280.

Fagiolini, A., Kupfer, D. J., Masalehdan, A., Scott, J. A., Houck, P. R., \& Frank, E. (2005). Functional impairment in the remission phase of bipolar disorder. Bipolar Disorders, 7(3), 281-285. doi : 10.1111/j.1399-5618.2005.00207.x

Feeney, J. A., Hohaus, L., Noller, P., \& Alexander, R. P. (2001). Becoming parents: Exploring the bonds between mothers, fathers, and their infants. New York, NY, US: Cambridge University Press.

Findley, M. J., \& Cooper, H. M. (1983). Locus of control and academic achievement: A literature review. Journal of Personality and Social Psychology, 44(2), 419-427. doi: 10.1037/0022-3514.44.2.419

Flouri, E. (2008). Fathering and adolescents' psychological adjustment: The role of fathers' involvement, residence and biology status. Child: Care, Health and Development, 34(2), 152-161. doi: 10.1111/j.1365-2214.2007.00752.x 
Gale, C. R., Batty, G. D., \& Deary, I. J. (2008). Locus of control at age 10 years and health outcomes and behaviors at age 30 years: The 1970 British Cohort Study. Psychosomatic Medicine, 70(4), 397-403. doi: 10.1097/PSY.0b013e31816a719e

Garber, J., Martin, N. C., Goodman, S. H., \& Gotlib, I. H. (2002). Negative cognitions in offspring of depressed parents: Mechanisms of risk. In Children of depressed parents: Mechanisms of risk and implications for treatment. (pp. 121-153). Washington, DC, US: American Psychological Association.

Geist, C. R., \& Borecki, S. (1982). Social avoidance and distress as a predictor of perceived locus of control and level of self-esteem. Journal of Clinical Psychology, 38(3), 611-613.

Gerdes, A., Hoza, B., Arnold, L., Pelham, W., Swanson, J., Wigal, T., et al. (2007). Maternal depressive symptomatology and parenting behavior: Exploration of possible mediators. Journal of Abnormal Child Psychology, 35(5), 705-714. doi: 10.1007/s10802-007-9134-3

Goodfellow, S. (1996). Having a baby in the Isle of Man. Unpublished Doctoral dissertation, University of Bristol, Bristol, U. K.

Goodman, R. (1997). The Strengths and Difficulties Questionnaire: a research note. Journal of Child Psychology and Psychiatry and Allied Disciplines, 38(5), 581-586. doi: 10.1111/j.1469-7610.1997.tb01545.x

Goodman, R., Ford, T., Richards, H., Gatward, R., \& Meltzer, H. (2000). The Development and Well-Being Assessment: description and initial validation of an integrated assessment of child and adolescent psychopathology. Journal of Child Psychology and Psychiatry and Allied Disciplines, 41(5), 645-655. doi: 10.1111/j.1469-7610.2000.tb02345.x

Goodman, R., Ford, T., Simmons, H., Gatward, R., \& Meltzer, H. (2000). Using the Strengths and Difficulties Questionnaire (SDQ) to screen for child psychiatric disorders in a 
community sample. The British Journal of Psychiatry, 177(6), 534-539. doi:10.1192/bjp.177.6.534

Goodman, S. H., Brand, S. R., Hersen, M., \& Gross, A. M. (2008). Parental psychopathology and its relation to child psychopathology. In Handbook of clinical psychology, vol 2: Children and adolescents. (pp. 937-965). Hoboken, NJ, US: John Wiley \& Sons Inc.

Hagekull, B., Bohlin, G., \& Hammarberg, A. (2001). The role of parental perceived control in child development: A longitudinal study. International Journal of Behavioral Development, 25(5), 429-437. doi: 10.1080/016502501316934851

Hipwell, A., Keenan, K., Kasza, K., Loeber, R., Stouthamer-Loeber, M., \& Bean, T. (2008). Reciprocal Influences Between Girls’ Conduct Problems and Depression, and Parental Punishment and Warmth: A Six year Prospective Analysis. Journal of Abnormal Child Psychology, 36(5), 663-677. doi: 10.1007/s10802-007-9206-4

Hoffman, M. A., \& Levy-Shiff, R. (1994). Coping and locus of control: Cross-generational transmission between mothers and adolescents. Journal of Early Adolescence, 14(3), 391-405. doi: 10.1177/0272431694014003005

Johnston, C., \& Mash, E. J. (2001). Families of children with Attention-Deficit/ Hyperactivity Disorder: Review and recommendations for future research. Clinical Child and Family Psychology Review, 4(3), 183-207. doi: 10.1023/A:1017592030434

Kalechstein, A. D., \& Nowicki, S., Jr. (1997). A meta-analytic examination of the relationship between control expectancies and academic achievement: An 11-yr follow-up to Findley and Cooper. Genetic, Social, and General Psychology Monographs, 123(1), 27-56. 
Kane, P., \& Garber, J. (2004). The relations among depression in fathers, children's psychopathology, and father-child conflict: A meta-analysis. Clinical Psychology Review, 24(3), 339-360. doi: 10.1016/j.cpr.2004.03.004

Keeton, C. P., Perry-Jenkins, M., \& Sayer, A. G. (2008). Sense of control predicts depressive and anxious symptoms across the transition to parenthood. Journal of Family Psychology, 22(2), 212-221. doi: 10.1037/0893-3200.22.2.212

Lamb, M. E. (1975). Fathers: Forgotten contributors to child development. Human Development, 18, 245-266. doi : 10.1159/000271493

Larson, L. M., Piersel, W. C., Imao, R. A., \& Allen, S. J. (1990). Significant predictors of problem-solving appraisal. Journal of Counseling Psychology, 37(4), 482-490. doi : 10.1037/0022-0167.37.4.482

Luoma, I., Tamminen, T., Kaukonen, P. l., Laippala, P., Puura, K., Salmelin, R., et al. (2001). Longitudinal study of maternal depressive symptoms and child well-being. Journal of the American Academy of Child \& Adolescent Psychiatry, 40(12), 1367-1374. doi : 10.1097/00004583-200112000-00006

Meltzer, H., Gatward, R., Goodman, R., \& Ford, T. (2000). Mental health of children and adolescents in Great Britain. London: Stationery Office.

Miner, J. L., \& Clarke-Stewart, K. A. (2008). Trajectories of externalizing behavior from age 2 to age 9: relations with gender, temperament, ethnicity, parenting, and rater. Developmental Psychology, 44(3), 771-786. doi:10.1037/0012-1649.44.3.771

Morton, T. L. (1997). The relationship between parental locus of control and children's perceptions of control. Journal of Genetic Psychology, 158(2), 216-225. 
O'Connor, T. G., Heron, J., \& Glover, V. (2002). Antenatal anxiety predicts child behavioral/emotional problems independently of postnatal depression. Journal of the American Academy of Child \& Adolescent Psychiatry, 41(12), 1470-1477. doi : 10.1097/00004583-200212000-00019

Phares, V., \& Compas, B. E. (1992). The role of fathers in child and adolescent psychopathology: Make room for daddy. Psychological Bulletin, 111(3), 387-412. doi : 10.1037/0033-2909.111.3.387

Ramchandani, P., Stein, A., Evans, J., \& O'Connor, T. G. (2005). Paternal depression in the postnatal period and child development: a prospective population study. Lancet, 365(9478), 2201-2205. doi : 10.1016/S0140-6736(05)66778-5

Roberts, M. W., Joe, V. C., \& Rowe-Hallbert, A. (1992). Oppositional child behavior and parental locus of control. Journal of Clinical Child Psychology, 21(2), 170-177.

Rodriguez, C. M., \& Richardson, M. J. (2007). Stress and Anger as Contextual Factors and Preexisting Cognitive Schemas: Predicting Parental Child Maltreatment Risk. Child Maltreatment, 12(4), 325-337. doi : 10.1177/1077559507305993

Rotter, J. B. (1966). Generalized expectancies for internal versus external control of reinforcement. Psychological Monographs, 80(1), 1-28.

Seeman, M. (1963). Alienation and social learning in a reformatory. American Journal of Sociology, 69, 270-284.

Sigmon, S. T., Pells, J. J., Boulard, N. E., Whitcomb-Smith, S., Edenfield, T. M., Hermann, B. A., et al. (2005). Gender differences in self-reports of depression: The response bias hypothesis revisited. Sex Roles, 53(5), 401-411. doi : 10.1007/s11199-005-6762-3 
Skopp, N. A., McDonald, R., Jouriles, E. N., \& Rosenfield, D. (2007). Partner aggression and children's externalizing problems: Maternal and partner warmth as protective factors. Journal of Family Psychology, 21(3), 459-467. doi : 10.1037/0893-3200.21.3.459

Steele, H., Steele, M., \& Fonagy, P. (1996). Associations among attachment classifications of mothers, fathers, and their infants. Child Development, 67(2), 541-555. doi: 10.1111/j.1467-8624.1996.tb01750.x

Stringer, S. A., \& La Greca, A. M. (1985). Correlates of child abuse potential. Journal of Abnormal Child Psychology, 13(2), 217-226. doi: 10.1007/BF00910643

Van den Bergh, B. R. H., \& Marcoen, A. (2004). High Antenatal maternal anxiety Is related to ADHD symptoms, externalizing problems, and anxiety in 8- and 9-year-olds. Child Development, 75(4), 1085-1097. doi: 10.1111/j.1467-8624.2004.00727.x

Verlaan, P., \& Schwartzman, A. E. (2002). Mother's and father's parental adjustment: Links to externalising behaviour problems in sons and daughters. International Journal of Behavioral Development, 26(3), 214-224. doi: 10.1080/01650250042000717

Wheatcroft, R., \& Creswell, C. (2007). Parents’ cognitions and expectations about their preschool children: The contribution of parental anxiety and child anxiety. British Journal of Developmental Psychology, 25, 435-441. doi: 10.1348/026151006X173288 


\section{Footnote}

${ }^{1}$ The teacher-report data were gathered using a modification of the SDQ response options intended to improve comparability of data across international samples. Specifically, the option "sometimes true” was substituted for "somewhat true”. The other two response options, "not true” and “certainly true” were consistent with Goodman’s (1997) published recommendation. 
Table 1: Parent demographic data.

\begin{tabular}{|c|c|c|c|}
\hline & $\begin{array}{l}\text { Mother } \\
\mathrm{N}=307\end{array}$ & $\begin{array}{l}\text { Father } \\
\mathrm{N}=307\end{array}$ & $\mathrm{t}$ \\
\hline Age at initial prenatal appointment $\mathrm{M}(\mathrm{SD})$ & $28.58(4.82)$ & $31.02(6.16)$ & $-8.83 * *$ \\
\hline \multicolumn{4}{|l|}{ Marital status at initial prenatal appointment } \\
\hline Single (never married) & $43(14.0 \%)$ & -- & \\
\hline Divorced/Separated & $15(4.9 \%)$ & -- & \\
\hline Married & $249(81.1 \%)$ & -- & \\
\hline \multicolumn{4}{|l|}{ Highest Education Level $^{\mathrm{a}}$} \\
\hline No qualifications & $48(15.6 \%)$ & $56(18.2 \%)$ & \\
\hline Skills & $31(10.1 \%)$ & $61(19.9 \%)$ & \\
\hline 'O' Levels & $105(34.2 \%)$ & $85(27.7 \%)$ & \\
\hline 'A' Levels & $34(11.0 \%)$ & $26(8.5 \%)$ & \\
\hline Teachers/Nurses & $20(6.5 \%)$ & $4(1.3 \%)$ & \\
\hline Degree+ & 69 (22.5\%) & 75 (24.4\%) & \\
\hline \multicolumn{4}{|l|}{ Ethnicity } \\
\hline Indigenous Manx & $59(19.2 \%)$ & $59(19.2 \%)$ & \\
\hline First generation Manx & $86(28.0 \%)$ & 95 (30.9\%) & \\
\hline Irish & $14(4.6 \%)$ & $23(7.5 \%)$ & \\
\hline Other & $148(48.2 \%)$ & $130(42.3 \%)$ & \\
\hline Pregnancy planned (n=303) & $202(66.7 \%)$ & -- & \\
\hline Prenatal CCEI ${ }^{1}$ Total Score M(SD) & $13.18(7.68)$ & $7.31(5.73)$ & $-12.28 * *$ \\
\hline Prenatal ANSIE ${ }^{2}$ Total Score M (SD) & 4.03 (1.99) & $3.86(2.17)$ & $1.19(\mathrm{NS})$ \\
\hline
\end{tabular}

${ }^{1}$ Crown Crisp Experiential Inventory; ${ }^{2}$ Adult Nowicki-Strickland Internal-External Scale. $* * \mathrm{p}<.001$. 
Table 2: Mean scores and standard deviations on all measures by child sex.

\begin{tabular}{|c|c|c|c|c|}
\hline & $\begin{array}{c}\text { All } \\
(n=307)\end{array}$ & $\begin{array}{c}\text { Boys } \\
(n=161)\end{array}$ & $\begin{array}{c}\text { Girls } \\
(n=146)\end{array}$ & \\
\hline & $\mathrm{M}(\mathrm{SD})$ & $\mathrm{M}(\mathrm{SD})$ & $\mathrm{M}(\mathrm{SD})$ & $\mathrm{t}$ \\
\hline Age in years & $7.8(.16)$ & $7.8(.14)$ & $7.8(.17)$ & 0.34 \\
\hline Mother's age in years & $28.58(4.82)$ & $28.04(4.82)$ & $29.16(4.77)$ & $-2.04 *$ \\
\hline Father's age in years & $31.02(6.16)$ & $30.78(6.23)$ & $31.30(6.10)$ & -0.74 \\
\hline \multicolumn{5}{|l|}{ Mother's Prenatal CCEI ${ }^{1}$ Total } \\
\hline Score & 13.18 (7.68) & $13.30(8.14)$ & $13.05(7.15)$ & 0.29 \\
\hline \multicolumn{5}{|l|}{ Father's Prenatal CCEI ${ }^{1}$ Total } \\
\hline Score & $7.31(5.73)$ & $6.98(5.18)$ & $7.67(6.29)$ & -1.06 \\
\hline \multicolumn{5}{|l|}{ Mother's Prenatal ANSIE ${ }^{2}$} \\
\hline Score & 4.03 (1.99) & $4.10(2.02)$ & $3.95(1.96)$ & 0.68 \\
\hline Father's Prenatal ANSIE ${ }^{2}$ Score & $3.86(2.17)$ & $4.20(2.18)$ & $3.49(2.10)$ & $2.91 * *$ \\
\hline $\mathrm{SDQ}^{3}$ Total Score & $5.85(5.48)$ & $7.10(5.83)$ & $4.47(4.74)$ & $4.35 * * *$ \\
\hline SDQ Prosocial & $2.01(2.13)$ & $2.71(2.26)$ & $1.23(1.66)$ & $6.56 * * *$ \\
\hline SDQ Activity & $2.52(2.55)$ & $3.34(2.69)$ & $1.62(2.03)$ & $6.35 * * *$ \\
\hline SDQ Emotional Problems & $1.59(1.92)$ & $1.57(1.99)$ & $1.61(1.85)$ & -0.20 \\
\hline SDQ Peer Relations & $2.65(1.01)$ & $2.68(1.06)$ & $2.61(0.95)$ & 0.64 \\
\hline SDQ Conduct Problems & $0.83(1.47)$ & $1.17(1.72)$ & $0.45(1.02)$ & $4.41 * * *$ \\
\hline DAWBA $^{4}$ Total Score & $13.12(11.75)$ & $16.92(12.43)$ & $8.93(9.33)$ & $6.39 * * *$ \\
\hline
\end{tabular}


${ }^{1}$ Crown Crisp Experiential Inventory; ${ }^{2}$ Adult Nowicki-Strickland Internal-External Scale; ${ }^{3}$ Strengths and Difficulties Questionnaire; ${ }^{4}$ Development and Well Being Assessment. 
Table 3: Zero-Order Spearman Correlations among the independent and dependent variables $\left(n=307-S D Q ; n=305-D A W B A^{1}\right)$.

$\begin{array}{llllllllll}1 & 2 & 3 & 4 & 5 & 6 & 7 & 8 & 9 & 10\end{array}$

1. DAWBA ${ }^{1}$ Total

2. $\mathrm{SDQ}^{2}$ Total

3. Mother's LOCR ${ }^{3}$

4. Father's LOCR ${ }^{3}$

5. Marital Status (T1)

6. Mother's age

7. Father's age

8. Mother's education

9. Father's education

10. CCEI ${ }^{4}$ Total (Mother)

11. CCEI ${ }^{4}$ Total (Father)
1.00

$.72 * *$

$.12^{*} \quad .15^{* *}$

$.23 * * \quad .20 * * \quad .29 * *$

$\begin{array}{llll}-.05 & -.04 & -.20 * * & -.26 * *\end{array}$

$\begin{array}{lllll}-.13 * & -.13 * & -.09 & -.15^{* *} & .36 * *\end{array}$

$\begin{array}{llllll}-.15 * & -.12 * & -.09 & -.11 & .19 * * & .64 * *\end{array}$

$\begin{array}{lllllll}-.18 * * & -.22 * * & -.40 * * & -.14 * & .08 & .08 & .07\end{array}$

$\begin{array}{llllllll}-.21 * * & -.20 * * & -.28 * * & -.37 * * & .17 * * & .16 * * & .13 * & .39 * *\end{array}$

$\begin{array}{lllllllll}.12 * & .09 & .18 * * & .03 & -.10 & -.04 & -.07 & -.08 & .001\end{array}$

.03

$\begin{array}{llll}.17 * * & .24 * * & -.20 * * & -.04\end{array}$

$-.03$

$-.09$

$-.15^{*} \quad .27^{* *}$

${ }^{1}$ Development and Well Being Assessment; ${ }^{2}$ Strengths and Difficulties Questionnaire; ${ }^{3}$ Locus of Control of Reinforcement as measured by the Adult Nowicki-Strickland Internal-External Scale; ${ }^{4}$ Crown Crisp Experiential Inventory. 